\title{
Application of WRF weather model to forecast precipitation in Nilwala river basin
}

\author{
K.D.W. Nandalal, D.A. Sachindra and U.R. Ratnayake
}

\begin{abstract}
The Weather Research and Forecasting (WRF) model is a numerical weather prediction and atmospheric simulation system designed for both research and operational applications. It was fine tuned to forecast precipitation over Nilwala river basin in Sri Lanka by investigating the impacts of its physics options on precipitation forecasting. In model fine tuning, impacts of microphyics schemes, cumulus schemes, land surface schemes, boundary layer schemes and long/shortwave schemes were investigated. Model predictions were compared with observed point rainfall data for three rainfall events to find reasonably good physics combinations. It was seen that the model combination, Ferrier microphysics scheme, Kain-Fritsch cumulus scheme, Rapid Update Curve land surface scheme, Yonsei boundary layer scheme, Rapid Radiative Transfer model longwave radiation scheme and Dudhia shortwave scheme yields good precipitation predictions over the basin when compared with the other physics combinations tested.
\end{abstract}

Keywords: Precipitation forecasting, weather models, physics options in weather models

\section{Introduction}

Human activities and many sectors of economy depend on weather and climate in different ways. Some rely on average conditions while others are sensitive to extremes. Also, they may depend upon variability making weather sequences important. The economic and social benefits of accurate weather forecasts are immense and include improved efficiencies in agricultural systems, energy generation, transportation systems, etc., and more importantly enhanced public safety.

The art of weather forecasting began with early civilizations using recurring astronomical and meteorological events to help them monitor seasonal changes in the weather. With the formation of regional and global meteorological observation networks in the nineteenth and twentieth centuries, more data became available for observation-based weather forecasting (Trenberth et al., 2000). Weather forecasts provide critical information about the weather to come. There are many different techniques involved in weather forecasting, from relatively simple observation of the sky to highly complex numerical models run on computers.

A numerical atmospheric model is a mathematical model constructed around a set of primitive dynamic equations that govern atmospheric motions. In today's world, it is a computer program that produces meteorological information for future times at given positions and altitudes. The primitive equations are a set of nonlinear differential equations that are used to approximate global atmospheric conditions. They consist of three main sets of equations: 1) conservation of momentum, 2) thermal energy equations, and $3)$ continuity equation. The atmosphere is a fluid. Basic idea of numerical weather prediction is to sample the state of the fluid at a given time and use the equations of fluid dynamics and thermodynamics to estimate the state of the fluid at some time in the future.

The realm of atmospheric models can be subdivided into several categories such as climate models, weather models, atmospheric dispersion models, etc. Weather models could be further classified into two distinct groups, namely, global weather models and regional weather models. Global weather models predict weather conditions over the whole globe while regional weather models confine their predictions to a predefined limited area. Output of a global model is taken as input to a regional model. The process of ingesting the output of a global model into a regional model and predicting future weather conditions is called downscaling of weather.

\footnotetext{
Eng. (Prof.) K.D.W. Nandalal, C Eng., FIE(Sri Lanka), BScEng, MEng, PhD, Professor of Civil Engineering, Department of Civil Engineering, University of Peradeniya. D.A. Sachindra, BScEng, MSc,

PhD Candidate, Victoria University. Melbourne, Australia. Eng. (Dr.) U.R. Ratnayake, C Eng., MIE(Sri Lanka), BScEng, MEng, Deng, Senior Lecturer, Department of Civil Engineering, University of Peradeniya.
} 


\subsection{Weather Research \& Forecasting model}

Weather Research and Forecasting (WRF 3.0) model is a numerical weather prediction and atmospheric simulation system designed for both research and operational applications. It falls into the category of regional weather models.

The development of the WRF model has been a multi-agency effort to build a next-generation mesoscale forecast model and data assimilation system to advance the understanding and prediction of mesoscale weather and accelerate the transfer of research advances into operations. The WRF effort has been a collaborative one among the National Center for Atmospheric Research's (NCAR) Mesoscale and Microscale Meteorology (MMM) Division, the National Oceanic and Atmospheric Administration's (NOAA) National Center for Environmental Prediction (NCEP) and Earth System Research Laboratory (ESRL), the Department of Defense's Air Force Weather Agency (AFWA) and Naval Research Laboratory (NRL), the Center for Analysis and Prediction of Storms (CAPS) at the University of Oklahoma, and the Federal Aviation Administration (FAA), with the participation of university scientists (Skamarock et al., 2008).

The WRF model is armed with many options for physics schemes that could be varied to fine tune the model to suite to its operating environment. Microphysics scheme, cumulus scheme, land surface scheme, boundary layer scheme and long/short wave radiation schemes are the different physics schemes available in the WRF model. Each of these physics schemes contains diverse options that could be selected to suit to local conditions.

Grantinger (2008) applied the WRF model over Europe and Africa. Kumar et al. (2008) studied its applicability in India while Pathirana (2005) used it to forecast rainfall in Mekong basin. Heikkila et al. (2008) investigated its use for Norway.

\subsection{Physics schemes in the WRF model}

\section{Microphysics scheme}

The WRF 3.0 model has a number of optional microphysics options; Kessler scheme, Lin et al scheme, WSM3 scheme (WRF Single Moment 3 class scheme), WSM5 scheme (WRF Single Moment 5 class scheme), WSM6 scheme (WRF
Single Moment 6 class scheme), Ferrier scheme, Thompson scheme and Morrison scheme.

Kessler scheme (Kessler, 1969), which was taken from the COMMAS (Collaborative Model for Multi-scale Atmospheric Simulation) model (Wicker and Wilhelmson, 1995), is a simple warm cloud scheme that includes water vapour, cloud water and rain. Lin et al scheme has six classes of hydrometeors including water vapour, cloud water, rain, cloud ice, snow and graupel. WSM3 scheme predicts three categories of hydrometeors: vapour, cloud water/ice and rain/snow, which is at times called simple-ice scheme. WSM5 scheme is similar to the WSM3 simple ice scheme. However, vapour, rain, snow, cloud ice, and cloud water are held in five different arrays. WSM6 scheme is a six-class scheme that extends the WSM5 scheme to include graupel and its associated processes. Ferrier scheme predicts changes in water vapour and condensate in the forms of cloud water, rain, cloud ice and precipitation ice (snow/graupel/sleet). Thompson scheme is a new bulk microphysical parameterization (BMP), which has been developed for use with the WRF model or other mesoscale models. Compared to earlier single-moment BMPs the new scheme incorporates a large number of improvements to both physical processes and computer coding. Morrison scheme is based on two-moment bulk microphysics scheme (Morrison et al., 2005, 2006). Six forms of water are included: vapour, cloud droplets, cloud ice, rain, snow and graupel/hail. The scheme variables include a number of concentrations and mixing ratios of cloud ice, rain, snow and graupel/hail, and mixing ratios of cloud droplets and water vapour (total of 10 variables). The prediction of two-moments (i.e., both number of concentration and mixing ratio) allows for a more robust treatment of the particle size distributions (Skamarock et al., 2008).

\section{Cumulus scheme}

The WRF model is armed with several options for the cumulus scheme, namely, Kain-Fritsch, Betts-Miller-Janjic, Grell-Devenyi and New Grell. The cumulus parameterization scheme in the WRF model is one of the physics options in the model, which takes the effect of cloud convection into account in predicting weather. The direct concern of the cumulus scheme is to predict convective precipitation. 
Cumulus convection plays an important role in determining the behaviour of weather and global climate systems. Yet, for weather and climate prediction models the physical processes associated with cumulus convection occur on scales that cannot be resolved by the models. Representation of the effects of the cumulus convection in numerical models is known as cumulus parameterization which is of fundamental importance in atmospheric sciences (Kuo et al., 1996).

\section{Land surface scheme}

The land surface scheme plays a vital role in the WRF model since it incorporates interactions between the land surface and the atmosphere (land-atmosphere processes). Basic element of land-atmosphere interaction is the exchange of moisture and energy between the two systems. The options available in the WRF model are Noah land surface model, 5-layer thermal diffusion model (default option) and Rapid Update Cycle (RUC) model.

Land surface scheme/models use atmospheric information from the surface layer scheme, radiative forces from the radiation scheme and precipitation from the microphysics and convective schemes, together with internal information on the land's state variables and land surface properties, to provide heat and moisture fluxes over land points and sea-ice points. Land surface models have various degrees of sophistication in dealing with thermal and moisture fluxes in multiple layers of the soil and also may handle vegetation, root, and canopy effects and surface snow cover prediction (Skamarock et al., 2008).

The minimum resolution requirements of the advanced land surface model are at least two soil layers, and one canopy layer, this is because the top thin soil layer responds faster with the diurnal cycle while the deeper layer controls the seasonal changes (Deardorff, 1977).

Noah land surface model in the WRF model is a 4-layer soil temperature and moisture model with canopy moisture and snow cover prediction. The layer thicknesses are 10, 30, 60 and $100 \mathrm{~cm}$ from the top to bottom. The total soil depth is $2 \mathrm{~m}$, with the root zone in the upper $1 \mathrm{~m}$ of soil. It includes root zone, evapotranspiration, soil drainage, and runoff, taking into account vegetation categories, monthly vegetation fraction, and soil texture (Skamarock et al., 2008). It has one canopy layer and the following variables: soil moisture and temperature in the soil layers, water stored on the canopy and snow stored on the ground $(X \mathrm{i}$, 2007).

RUC land surface model has a multi-layer soil model (6 layers of soil) with higher resolution in the top part of soil domain $(0,5,20,40,160$, $300 \mathrm{~cm}$ is default) (Smirnova et al., 1997, 2000). The RUC and Noah schemes are intermediate in detail and the major deference between them is that RUC has a multi-layer snow scheme and Noah has a single snow layer lumped with the topmost soil layer (Jin and Miller, 2007).

The 5-layer thermal diffusion model is based on the MM5 (NCAR mesoscale model) 5-layer soil temperature model. Layers are 1, 2, 4, 8 and 16 $\mathrm{cm}$ thick. The energy budget includes radiations, and sensible and latent heat fluxes. It also allows for a snow-cover flag, but the snow cover is fixed in time. Soil moisture is also fixed with a land use and season-dependent constant value, and there are no explicit vegetation effects $(\mathrm{Xi}, 2007)$. Soil moisture is also fixed with land use and season dependent constant values, and there are no explicit vegetation effects (Skamarock et al., 2008).

\section{Boundary layer scheme}

The lowest layer of the atmosphere, troposphere, can be divided into two parts: the planetary boundary layer (PBL) extending upward from the surface to a height that ranges anywhere from 100 to $3000 \mathrm{~m}$ and above it. The boundary layer is directly influenced by the presence of the Earth's surface, responding to such forces as frictional drag, solar heating and evapotranspiration. Each of these forces generates turbulence/eddies, which can be as deep as the boundary layer itself.

The WRF model includes NCEP GFS (Global Forecast System) scheme, ACM2 (Asymmetric Convective Model, version 2) scheme, MRF (Medium Range Forecast) scheme, MellorYamada-Janjic (Eta) scheme and Yonsei University (YSU) scheme under its planetary boundary layer options.

During the summer, the planetary boundary layer can reach heights of 1 to $1.5 \mathrm{~km}$ above the land surface and it can even reach a height of $5 \mathrm{~km}$ over a hot desert. The thickness of the surface layer is about $1 / 10$ of the boundary layer. 


\section{Longwave and Shortwave radiation schemes}

Similar to other weather models the WRF model takes the effects of radiation into account in producing forecasts. The WRF model employs two types of separate radiation schemes, one for shortwave radiation and the other for longwave radiation. It includes several short/longwave radiation schemes that could be varied to see the impacts on precipitation forecasts. For shortwave radiation schemes the WRF model contains Dudhia scheme (Model default), Goddard scheme, CAM (Community Atmospheric Model) shortwave scheme and GFDL (Geophysical Fluid Dynamic Laboratory) shortwave scheme. Meanwhile RRTM (Rapid Radiative Transfer Model) scheme (WRF Model default), CAM scheme and GFDL schemes are available as longwave radiation options in the WRF model.

The radiation schemes provide atmospheric heating due to radiative flux divergence and surface downward longwave and shortwave radiation for the ground heat budget. Longwave radiation includes infrared or thermal radiation absorbed and emitted by gases and surfaces. Upward longwave radiative flux from the ground is determined by the surface emissivity that in turn depends upon land-use type, as well as the ground (skin) temperature. Shortwave radiation includes visible and surrounding wavelengths that make up the solar spectrum. The processes include absorption, reflection, and scattering in the atmosphere and at surfaces (Skamarock et al., 2008).

In addition, the model demonstrates other phenomena such as the reflection of radiation by clouds and the Earth's surface, the scattering of radiation by clouds and aerosols, and the reemission of longwave radiation by ozone.

The paper presents a study carried out to investigate impact of different options available for the physics schemes in the WRF model on rainfall predictions on its application to Nilwala river basin in Southern Sri Lanka. In the study the impacts of different options available for microphysics scheme, cumulus scheme, land surface scheme, boundary layer scheme and radiation schemes in the WRF model on precipitation predictions were observed.

\section{Site Description}

The Nilwala river is one of the longest rivers in Southern Sri Lanka. It originates at Panilkanda at an altitude of 1,050 $\mathrm{m}$ above MSL and after traversing about $72 \mathrm{~km}$ the river meets the Indian Ocean at Matara. Nearly 90 per cent of the area covered by the catchment of Nilwala river belongs to the Matara district. The area of the river basin is approximately $1,073 \mathrm{~km}^{2}$. It lies mainly in the Matara district within the latitude $5^{\circ} 55^{\prime}-6^{\circ} 13^{\prime}$ and longitude $80^{\circ} 25^{\prime}-80^{\circ}$ $38^{\prime}$. Figure 1 shows the Nilwala river basin. The river basin consists of two distinct zones. The upper basin upto Pitabeddara is a hilly piece of land while the lower basin is quite flat. This lower basin extending inland up to about $12 \mathrm{~km}$ from the coastline is subjected to severe flooding with southwest monsoonal rains experienced from May to June and with convectional and cyclonic activities from October to November (Elkaduwa and Sakthivadivel, 1998).

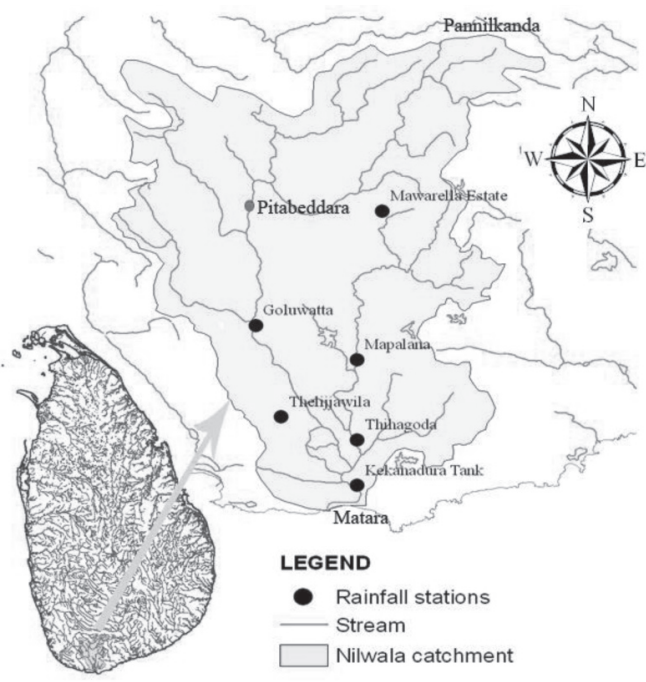

Figure 1 - Nilwala river basin 


\section{Methodology and Analysis}

\subsection{Domain configuration and forecast time}

Selection of a reasonably good domain configuration and a forecast period is important. Though a finer spatial resolution can improve the quality of predictions, it tends to take longer model run time to produce results and demands superior computer resources for the simulations, which ultimately raise the computation cost. Therefore, a healthy balance between the accuracy and computation cost had to be considered in the study. Though weather forecasting needs to be done as accurately as possible, a suitably coarse domain configuration was selected to obtain a feasible approximate solution.

Initially three different domain configurations with the same spatial extent were compared. Three domain configurations tested were, (i) 30 $\mathrm{km} / 10 \mathrm{~km} / 3.3 \mathrm{~km}$, (ii) $90 \mathrm{~km} / 30 \mathrm{~km} / 10 \mathrm{~km}$ (iii) $45 \mathrm{~km} / 15 \mathrm{~km} / 5 \mathrm{~km}$. Spatial extents of domain were maintained as 1800x1800 $\mathrm{km} / 645 x 645 \mathrm{~km} / 245 \times 245 \mathrm{~km}$, respectively for the $1^{\text {st }} 2^{\text {nd }}$ and $3^{\text {rd }}$ domains. All the domains shared the same centre. Figure 2 depicts the arrangement of the three domains nested for the model runs.

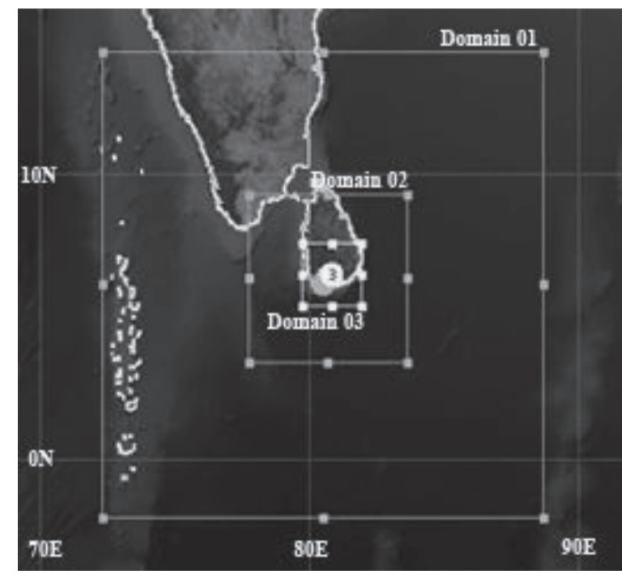

Figure 2 - The arrangement of three domains over the Nilwala river basin

Initial and lateral boundary conditions for the WRF model were obtained from the Global Forecast System (GFS) (Awad et al., 2007). The GFS model, which is run by NCEP, was initialized using observed data from radiosondes weather satellites and surface weather observations. Two global data sets were downloaded from the GFS on 09/12/2008 and 19/03/2009 for deciding prediction time and domain configuration.
The WRF model was initially applied to the study area with its default physics options; WSM3 microphysics scheme, Kain Fritch cumulus scheme, 5-layer thermal diffusion land surface scheme, YSU boundary layer scheme, RRTM long wave radiation scheme, Dudhia short wave radiation and Monin-Obukhov surface layer option. The model was run on a dual processor (each $2.4 \mathrm{GHz}$ ) computer with a RAM (Random Access Memory) of 1.5 GB.

The time duration required to complete a model run with different domain configurations were obtained. The model prediction accuracy was checked with point rainfall data obtained from rainfall stations at Mapalana, Kekanadura tank, Thihagoda, Thelijjawila, Goluwatta and Mawarella Estate. Results indicated that the $90 \mathrm{~km} / 30 \mathrm{~km} / 10 \mathrm{~km}$ domain configuration was too coarse while $30 \mathrm{~km} / 10 \mathrm{~km} / 3.3 \mathrm{~km}$ domain was taking a very high run time although it showed better accuracy. The time needed to complete a model run of $72 \mathrm{~h}$ prediction with the above mentioned three domain configurations were $26 \mathrm{~h}, 8 \mathrm{~h}$ and $1.5 \mathrm{~h}$, respectively. Rainfall prediction times of $72 \mathrm{~h}, 48 \mathrm{~h}$ and $24 \mathrm{~h}$ were used to study the impact of prediction time. The results indicated that the accuracy drops considerably with the increase in the prediction time. Therefore, finally the $45 \mathrm{~km} / 15 \mathrm{~km} / 5 \mathrm{~km}$ domain configuration (domain sizes; $1800 \times 1800 \mathrm{~km} / 645 \times \quad 645 \mathrm{~km} \quad / 245 \times 245 \mathrm{~km}$ ) was selected to forecast rainfall up to $24 \mathrm{~h}$ into future.

\subsection{Investigation of impacts of model physics on precipitation predictions}

Selection of the most appropriate options for the diverse physics schemes in the WRF model is important for the correct forecasting of precipitation by the model for a certain area. Thus, the most suitable physics options for the model to predict precipitation of the Nilwala river basin was carried out based on three sets of data obtained from the GFS on 09/12/2008, 19/03/2009 and 05/04/2009. The Nilwala river basin has received considerable rainfall during these three days within the period for which GFS data were available. The tests devised to select the most suitable options for microphysics scheme, cumulus scheme, land surface scheme, boundary layer scheme and long/short wave radiation scheme, are given in Table 1. Identification of the most suitable options for the above physics schemes was 


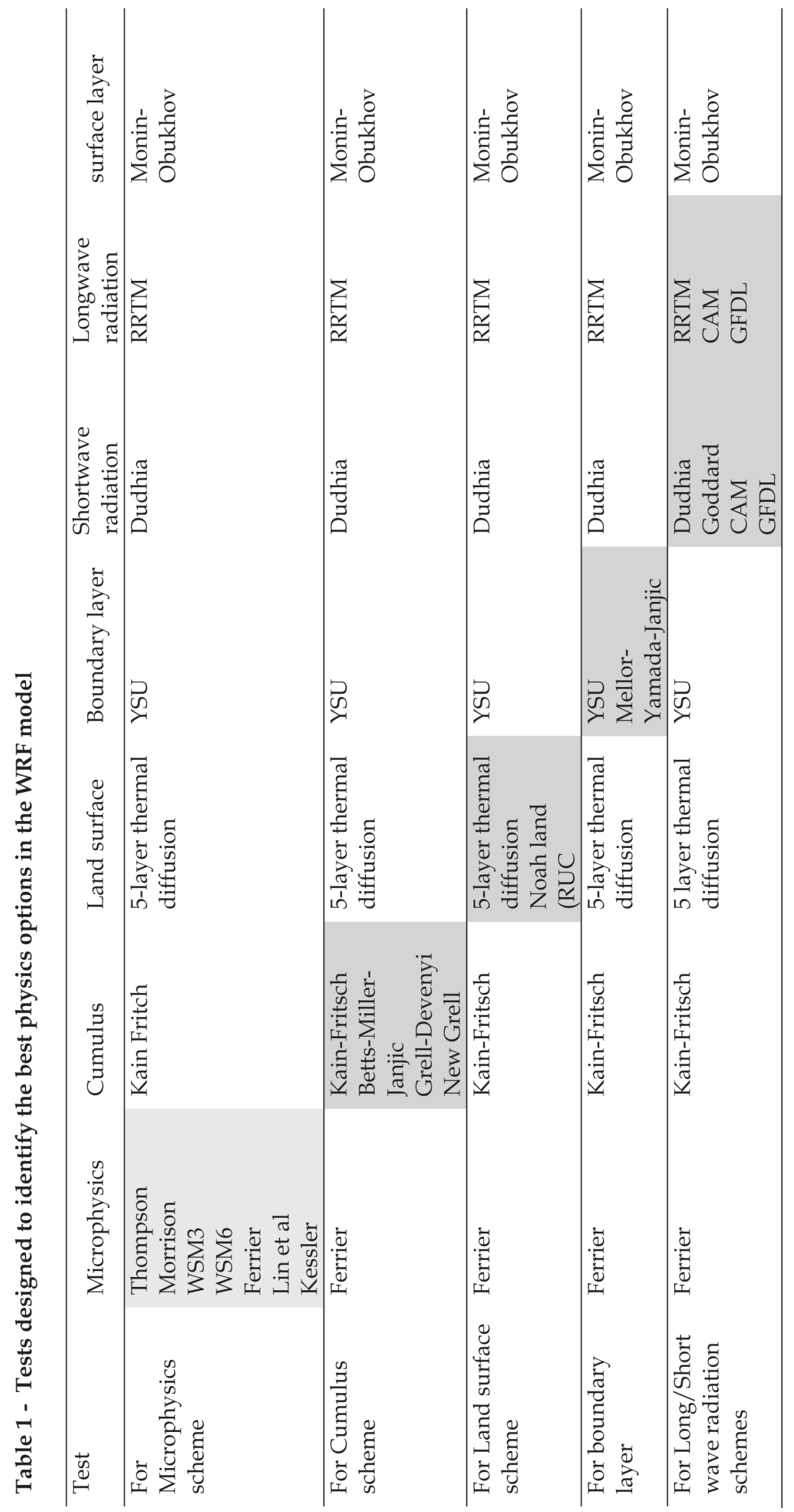



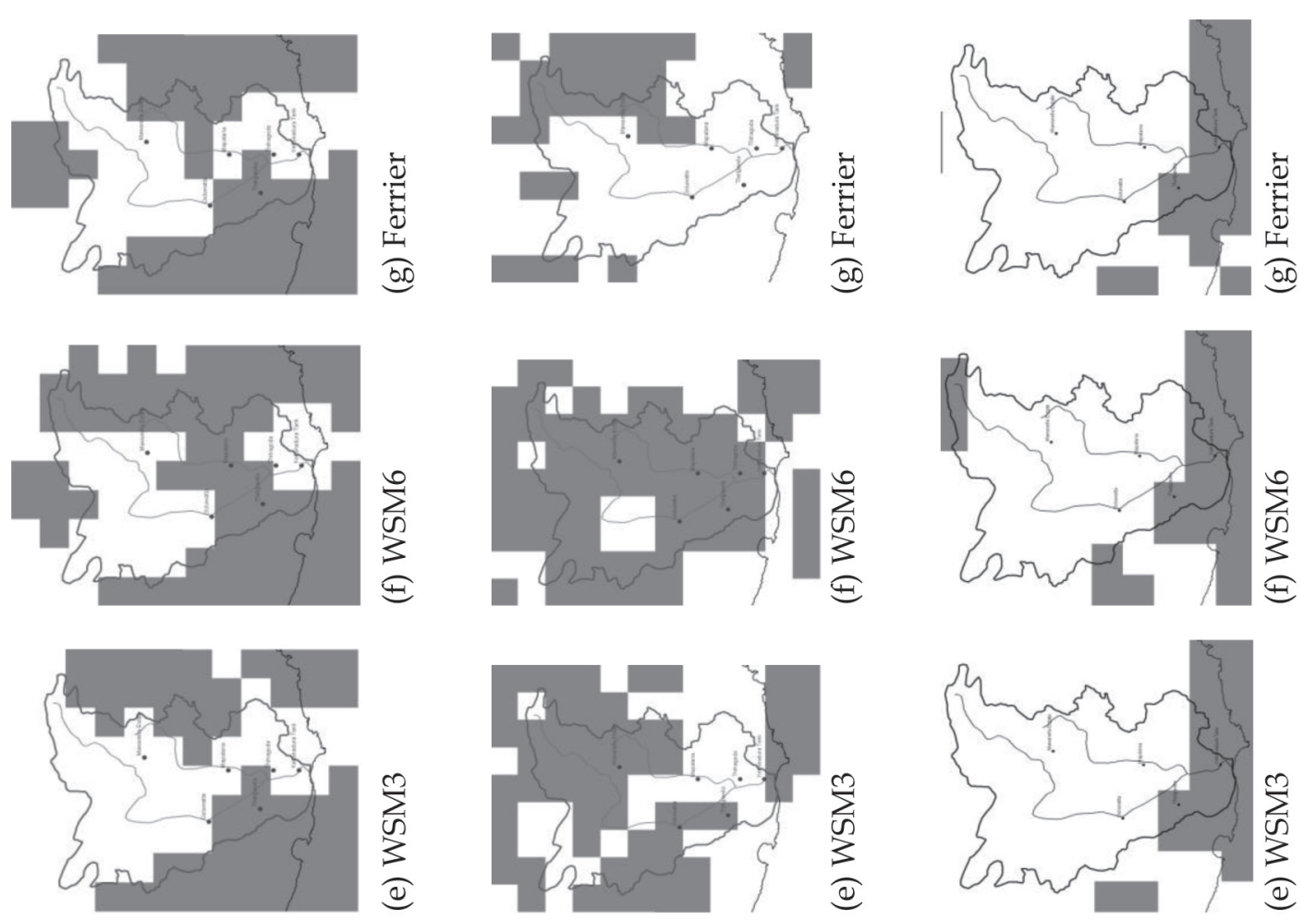

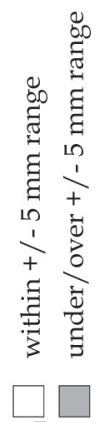


竎
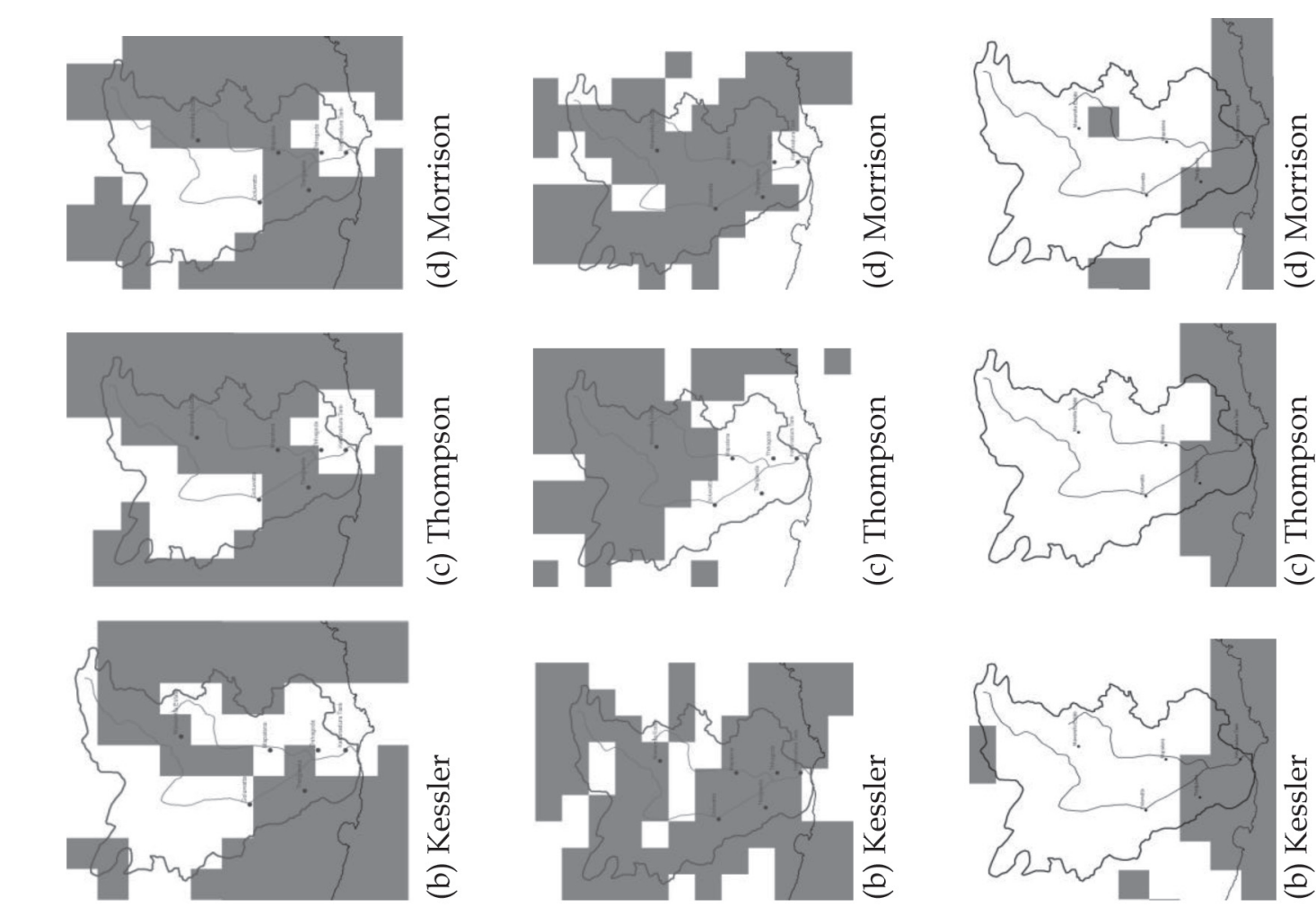

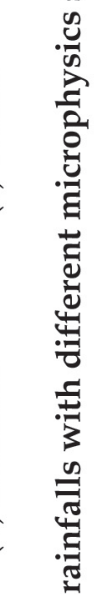
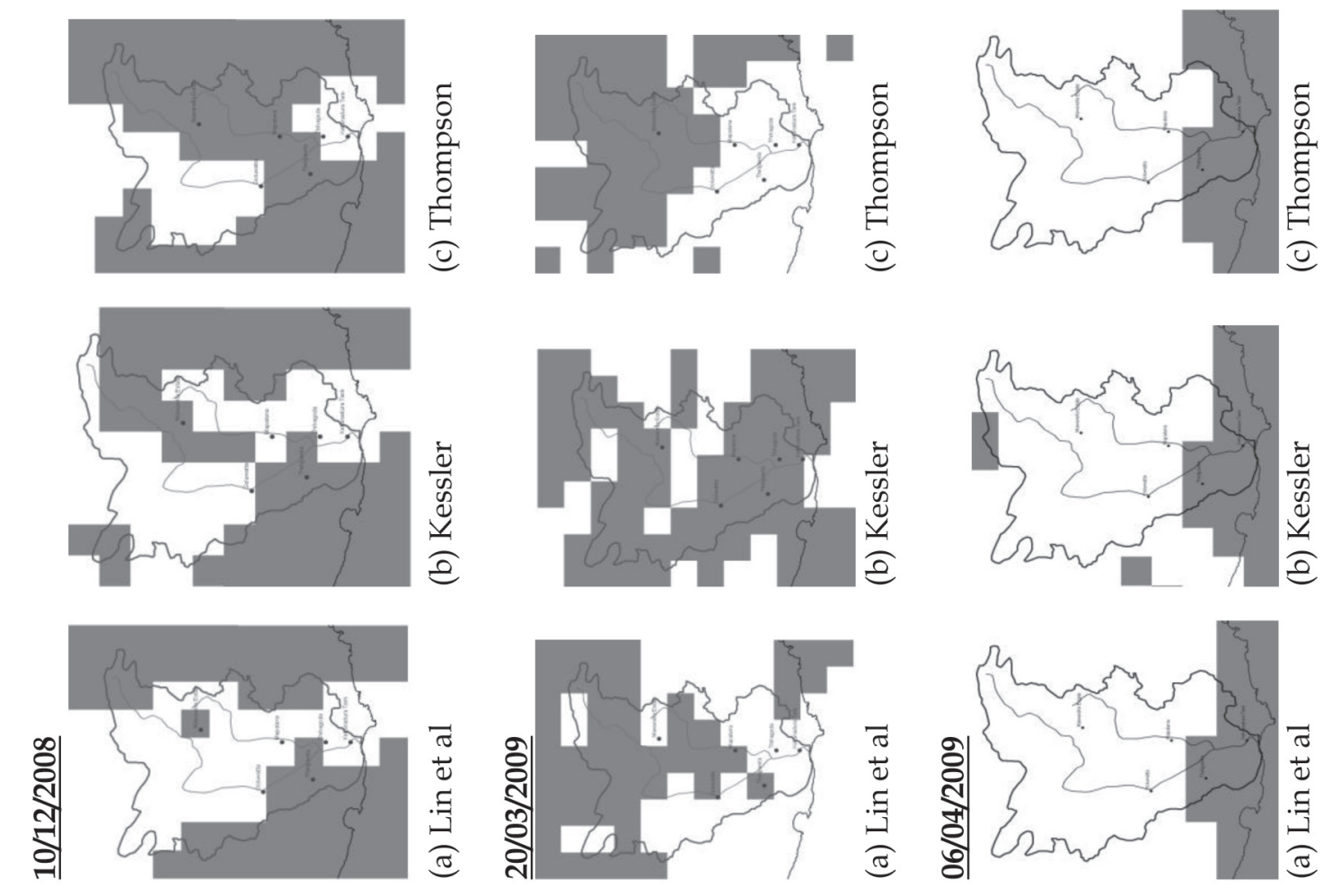
based on a search method in which the most appropriate options for the physics schemes were successively obtained while the identified options were used in subsequent calculations.

\section{Microphysics scheme}

The microphysics scheme in WRF is the most influential physics option in precipitation forecasting (Otkin et al., 2006). Thus, impact of different optional microphysics schemes was investigated first. The test was to identify the best option for the microphysics scheme from those that are available n the WRF model, viz., Thompson, Morrison, WSM3, WSM6, Ferrier, Lin et al and Kessler. As Table 1 indicates at this step the other physics schemes were kept fixed at the options given in it. The option which produced the best results for the three sets of downloaded data was selected and it was executed in all the subsequent model runs. The comparison of the options based on predicted and observed rainfalls on the three days is shown in Figure 3.

White colour cells denote acceptable precipitation predictions falling into $+/-5 \mathrm{~mm}$ range while grey cells depict predictions outside the range. Ability to predict rainfall within this range is assumed to be acceptable for rainfall prediction in the catchment. To visualize the goodness of predictions a parameter called correctly predicted area percentage (CPA \%), which is defined as the area inside the basin in which the predictions were within the above specified $+/-5 \mathrm{~mm}$ range expressed as a \% of the total basin area, was used. Table 2 gives CPA \% by different optional microphysics schemes.

Table 2 - CPA \% for different options for the microphysics scheme

\begin{tabular}{lccc}
\hline \multirow{2}{*}{ Option } & \multicolumn{3}{c}{ CPA \% } \\
\cline { 2 - 4 } & $10 / 12 / 08$ & $20 / 03 / 09$ & $06 / 04 / 09$ \\
\hline Lin et al & 66 & 55 & 88 \\
Kessler & 68 & 19 & 86 \\
Thompson & 40 & 37 & 88 \\
Morrison & 46 & 16 & 88 \\
WSM3 $^{*}$ & 80 & 37 & 90 \\
WSM6 & 50 & 13 & 86 \\
Ferrier & 71 & 84 & 91 \\
\hline \multicolumn{3}{c}{ (*WRF 3.0 default option) }
\end{tabular}

According to the observations shown in Table 2 the Ferrier microphysics scheme in the WRF model produced the best rainfall forecast over the Nilwala river basin for the rainfall events on 10/12/2008, 20/03/2009 and 06/04/2009 with
CPA's of $71 \%, 84 \%$ and $91 \%$, respectively. Thus, the Ferrier microphysics scheme was selected as the most suitable option. Afterwards, it was used as the microphysics scheme in the selection of other physics schemes.

\section{Cumulus scheme}

Second test employed for the selection of the best option for the cumulus scheme is shown next in Table 1. As it indicates the options, Kain-Fritsch, Betts-Miller-Janjic, Grell-Devenyi and New Grell, available in the WRF model were studied. The comparison of predicted and observed rainfalls is presented in Figure 4. The correctly predicted area percentages are given in Table 3.

Table 3 - CPA \% for different options for the cumulus scheme

\begin{tabular}{lccc}
\hline \multirow{2}{*}{ Option } & \multicolumn{3}{c}{ CPA \% } \\
\cline { 2 - 4 } & $10 / 12 / 08$ & $20 / 03 / 09$ & $06 / 04 / 09$ \\
\hline Kain-Fritsch* & 63 & 82 & 91 \\
Betts-Mellor- & 39 & 55 & 57 \\
Janjic & & & \\
Grell & 9 & 22 & 97 \\
New Grell & 71 & 16 & 18 \\
\hline & & (*WRF 3.0 default option)
\end{tabular}

The results in Table 3 shows that for the rain events on the three days over the Nilwala river basin, the Kain-Fritsch (model default) produced reasonably good forecasts with CPA's of $63 \%, 82 \%$ and $91 \%$, respectively. Thus, it was selected as the best option for the cumulus scheme. However, the best predictions have been made by the New Grell cumulus scheme $(\mathrm{CPA}=71 \%) \quad$ Kain-Fritsch cumulus scheme $(\mathrm{CPA}=82 \%)$ and Grell cumulus scheme $(\mathrm{CPA}=97 \%)$ for the three events in order.

\section{Land surface scheme}

The third test given in Table 1 is for the identification of the best option for the land surface scheme. The options available in the WRF model are Noah land surface model, Rapid Update Cycle (RUC) and 5-layer thermal diffusion model. Figure 5 depicts the comparison of predicted and observed rainfall over the Nilwala river basin for the three days. The correctly predicted area percentages for the land surface options are given in Table 4 . 
Table 4 - CPA \% for different options for the Land surface scheme

\begin{tabular}{lccc}
\hline \multirow{2}{*}{ Option } & \multicolumn{3}{c}{ CPA \% } \\
\cline { 2 - 4 } & $10 / 12 / 08$ & $20 / 03 / 09$ & $06 / 04 / 09$ \\
\hline Noah & 50 & 61 & 88 \\
RUC* & 71 & 74 & 88 \\
Thermal & 63 & 82 & 91 \\
diffusion & & & \\
\hline
\end{tabular}

(*WRF 3.0 default option)
As Table 4 presents, for the three rain events RUC land surface model has responded with good CPA's of $71 \%, 74 \%$ and $88 \%$, respectively. The Thermal diffusion model has produced good rainfall forecast with CPA's of $63 \%, 82 \%$ and $91 \%$ on the three days and thus selected as the most appropriate option. All rain events have shown dependence on different land surface models, but it is negligible when compared to the influences of other physics options in the WRF model.

\section{$\underline{10 / 12 / 2008}$}

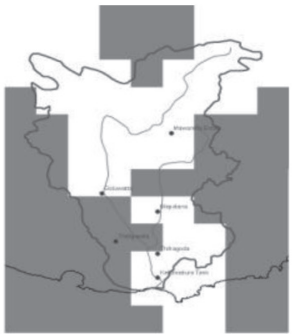

(a) Kain- Fritsch

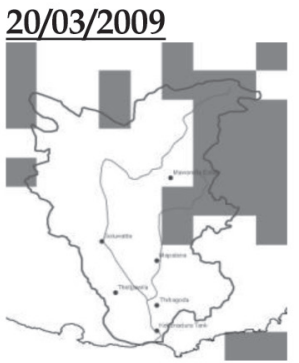

(a) Kain- Fritsch

\section{$\underline{06 / 04 / 2009}$}

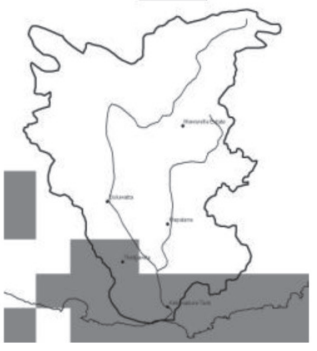

(a) Kain- Fritsch



(b) Betts-Miller

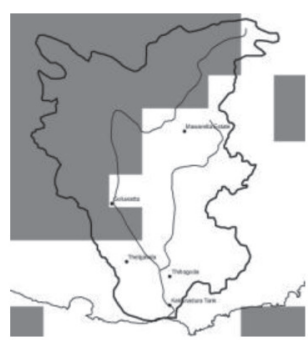

(b) Betts-Miller

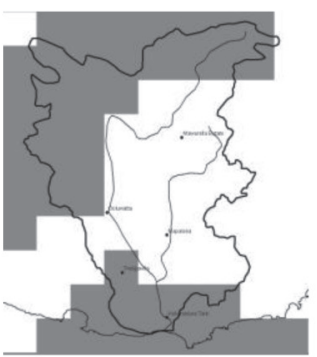

(b) Betts-Miller



(c) Grell

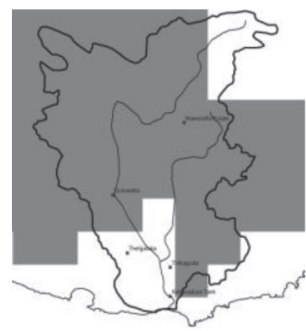

(c) Grell



(c) Grell

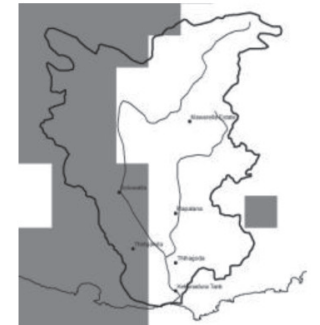

(d) New Grell

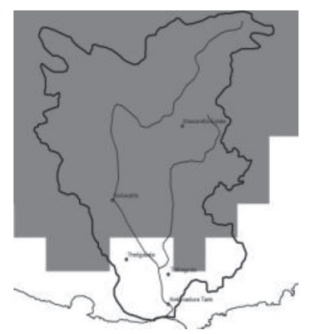

(d) New Grell

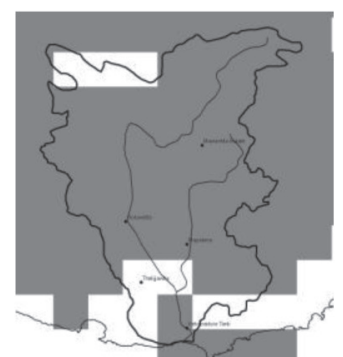

(d) New Grell

\section{Figure 4 - Difference between WRF prediction and observed rainfalls with}

different cumulus schemes

$\square$ within $+/-5 \mathrm{~mm}$ range

under/over $+/-5 \mathrm{~mm}$ range

\section{Boundary layer scheme}

The test for the identification of most suitable option for the boundary layer scheme out of YSU and Mellor-Yamada-Janjic (Eta) options was carried out next. Other than these the WRF model includes NCEP GFS, ACM2 and MRF options. These options were left out of the analysis since some of them were outdated. The comparison of predicted and observed rainfalls is presented in Figure 6. The correctly predicted area percentages are given in Table 5. 
Out of the two boundary layer options considered, the YSU option (model default) has been able to forecast the three rain events with almost equal success. The CPA's for the three rain events are $71 \%, 84 \%$ and $91 \%$, respectively. Therefore, YSU boundary layer option was selected for the WRF model to use it for the Nilwala river basin. Though the Mellor Yamada option has shown slight inconsistency in the predictions on 20/03/2009, it too could be regarded as a reasonably good boundary layer option.

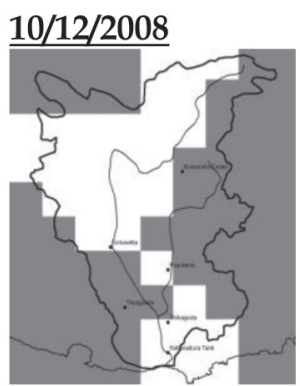

(a) Noah

20/03/2009

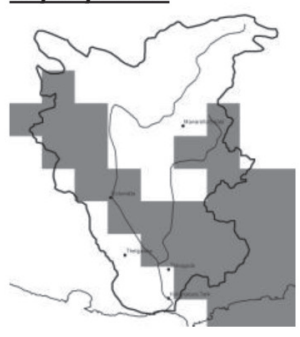

(a) Noah

06/04/2009

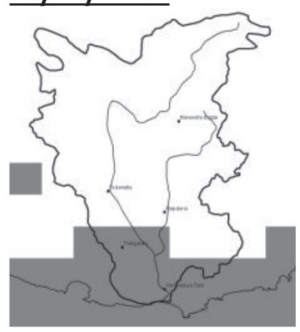

(a) Noah



(b) RUC



(b) RUC

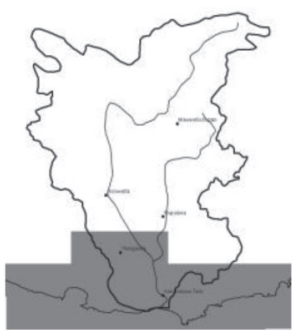

(b) RUC
Table 5 - CPA \% for different options for the boundary layer scheme

\begin{tabular}{lccc}
\hline \multirow{2}{*}{ Option } & \multicolumn{3}{c}{ CPA \% } \\
\cline { 2 - 4 } & $10 / 12 / 08$ & $20 / 03 / 09$ & $06 / 04 / 09$ \\
\hline Mellor & 80 & 52 & 81 \\
Yamada & & & 91 \\
YSU* & 71 & 84 & 91 \\
\hline & & (*WRF 3.0 default option)
\end{tabular}

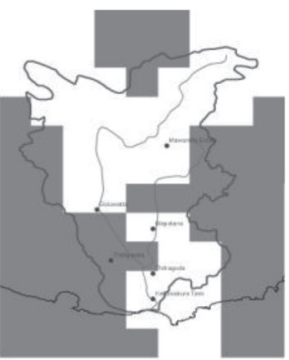

(c) Thermal diffusion



(c) Thermal diffusion

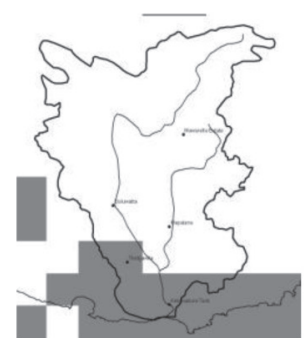

(c) Thermal diffusion

Figure 5 - Difference between WRF predictions and observed rainfalls with different land surface models

\section{Longwave and Shortwave radiation schemes}

Finally, the selection of the best options for the shortwave and longwave radiation schemes was carried out. The options studied for shortwave scheme were Dudhia scheme (Model default), Goddard scheme, CAM scheme, GFDL scheme and for longwave scheme were RRTM scheme (Model default), CAM scheme and GFDL scheme.
Results of the comparison of radiation schemes based on predicted and observed rainfalls are shown in Figure 7 and Table 6. 
Table 6 - CPA \% for different options for the radiation schemes

\begin{tabular}{lccc}
\hline \multirow{2}{*}{ Options } & \multicolumn{3}{c}{ CPA \% } \\
\cline { 2 - 4 } & $10 / 12 / 08$ & $20 / 03 / 09$ & $06 / 04 / 09$ \\
\hline RRTM $^{*}$, CAM & 75 & 21 & 87 \\
RRTM*, Goddard & 75 & 26 & 90 \\
CAM, CAM & 36 & 82 & 88 \\
GFDL, GFDL & 46 & 51 & 88 \\
CAM, Dudhia* $^{*}$ & 28 & 96 & 88 \\
RRTM $^{*}$, Dudhia* & 71 & 84 & 88 \\
\hline
\end{tabular}

(*WRF 3.0 default option)

Comparison of the performances of radiation schemes given in Table 6 shows that the RRTM longwave radiation scheme and Dudhia shortwave radiation scheme have produced good consistent results with CPA's of 71\%, $84 \%$ and $88 \%$ for the three rain events. The other shortwave and longwave option combinations tested have produced inconsistent results generating good predictions for some events while producing poor forecasts for the other events. The combinations which produced very inferior performances for all the three days are not presented in the comparison.

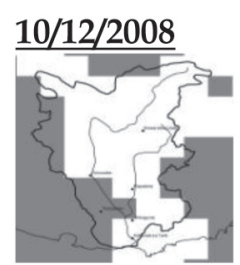

(a) Mellor Yamada 20/03/2009



(a) Mellor Yamada 06/04/2009

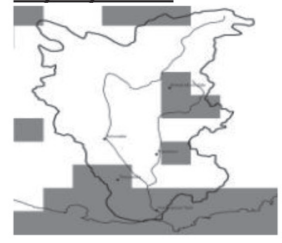

(a) Mellor Yamada

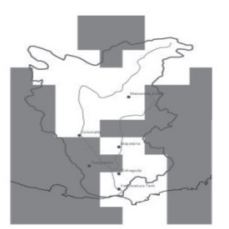

(b) YSU

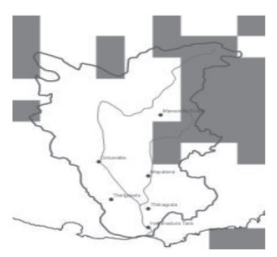

(b) YSU

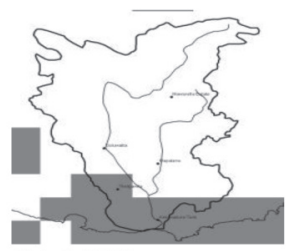

(b) YSU

Figure 6 - Difference between WRF predictions and observed rainfalls with different boundary layer schemes

within $+/-5 \mathrm{~mm}$ range

under/over $+/-5 \mathrm{~mm}$ range

\section{Conclusions}

All the tested microphysics schemes (Lin et al, Kessler, Thompson, Morrison, WSM3, WSM6 and Ferrier) show similar spatial distribution of accuracy over the basin for each individual rain event. In the case of rain events on 10/12/2008 and 06/04/2009 higher prediction accuracies have been observed over the upper Nilwala river catchment whereas for the rain event on 20/03/2009 prediction accuracies were low over the entire basin except with the Ferrier microphysics scheme. When it comes to the cumulus schemes a clear pattern of prediction accuracy over the basin was not observed. The prediction accuracy changed spatially from event to event as well as with different cumulus schemes used. The model default Kain-Fritsch cumulus scheme produced reasonably good CPA\% for all the three events. This scheme has been able to attain a good degree of accuracy over the upper basin in particular. In the case of land surface options executed in model runs Noah, RUC, and Thermal diffusion models have produced good predictions over the upper Nilwala river basin in all the three rain events. Even the spatial distribution of the prediction accuracies varied across the basin in a very unique manner to each individual rain event. The RUC could be taken as the most consistent land surface model among the three options tested. The RRTM longwave radiation scheme with Dudhia shortwave scheme has produced almost equally good rainfall predictions for the three rainfall events. More importantly these are the model default longwave and shortwave radiation options in the WRF model. Tested combinations of long/shortwave radiation 


schemes have shown spatial patterns of accuracies unique to rain events on 10/12/2008 and 06/04/2009. The rain event on 06/04/2009 has exhibited very little dependence on the combinations of long/shortwave radiation options considered. Mellor Yamada and YSU planetary boundary layer schemes have shown very little influence on the $\mathrm{CPA} \%$ and the spatial distribution of the accuracy of the predictions.

It could be concluded that considering the $\mathrm{CPA} \%$, the model physics combination consisting of Ferrier microphysics scheme, Kain-Fritsch cumulus scheme, RUC land surface scheme, RRTM longwave radiation scheme, Dudhia shortwave scheme and YSU planetary boundary layer scheme has yielded the best precipitation predictions over the Nilwala river basin for the three rainfall events considered.

\section{Acknowledgements}

The financial assistance provided by the National Science Foundation, Sri Lanka through its research grant RG/2007/W\&E/02 is gratefully acknowledged.

\section{References}

1. Awad, A.K.A,. Ajjaji, R. and Dhanhani, A. "Automatic Two-Way Nested WRF MiddleEast Numerical Weather Forecast Application", WRF user's workshop, 2007.

2. Deardorff, J.W. "Parameterization of Ground Surface Moisture Content for Use in Atmospheric Prediction Models", Journal of Applied Meteorology, 16, pp 1182-1185, 1977.

3. Elkaduwa, W.K.B. and Sakthivadivel, R. "Use of Historical Data as a Decision Support Tool in Watershed Management: A Case Study of the Upper Nilwala Basin in Sri Lanka", Research Report 26, International Water Management Institute, Colombo, Sri Lanka, 1998.

4. Grantinger, A. "Evaluation of WRF over Europe and Africa", WRF user workshop 2008, pp 8-12, 2008.

5. Heikkila, U., Mesquita, M. and Barstad, I. "Precipitation Downscaling on the West Coast of Norway: Comparison with Observational Network", WRF users workshop, 2008.
6. Jin, J. and Miller, N. "Intercomparison of the Performance of CLM3, NOAH, RUC, and STD Land Surface Schemes in the Weather and Research Forecasting Model", American Geophysical Union, Fall Meeting, 2007.

7. Kessler, E, "On the Distribution and Continuity of Water Substance in Atmospheric Circulation, Meteorological Monogram", 32, American Meteorological Society, pp84, 1969.

8. Kumar, A., Dudhia, J., Rotunno, R., Niyog, D. and Mohanty, U.C. "Analysis of the 26 July 2005 Heavy Rain Event over Mumbai, India using the Weather Research and Forecasting (WRF) Model", Quarterly Journal of the Royal Meteorological Society, 134, pp1897-1910, 2008.

9. Kuo, H.Y., Bresch, J.F., Cheng, M.D. and Kain, J. "Summary of a Mini Workshop on Cumulus Parametrization for Mesoscale Models", 1996.

10. Morrison, H., Curry, J.A. and Khvorostyanov, V. I. "A New DoubleMoment Microphysics Parameterization for Application in Cloud and Climate Models", Journal of Atmospheric Sciences, 62, pp

11. 1665-1677, 2005.

12. Morrison, H. and Pinto, J.O. "Intercomparison of Bulk Microphysics Schemes in Mesoscale Simulations of Springtime Arctic Mixed-Phase Stratiform Clouds", Monthly Weather Review, 134, pp 1880-1900, 2006.

13. Otkin, J. A, Huang, H.L and Seifert, A. "A Comparison of Microphysical Schemes in the WRF Model during a Severe Weather Event", Preprints, 7th Annual WRF User's Workshop, Boulder, CO, 2006.

14. Pathirana, A., Herath, S. and Swain, D. "Hydrometeorological input for Improving Flood Forecasting in the Mekong", Conference on Role of Water Sciences in Transboundary River Basin Management, Thailand, 2005.

15. Skamarock, W.C., Klemp, J.B., Dudhia,.J., Gill, D.O., Barker, D.M., Duda, M.G., Huang, X.Y, Wang, W. and Powers, J.G., "A Description of the Advanced Research WRF Version 3", NCAR Technical note, June 2008. 
16. Smirnova, T.G., Brown, J.M. and Benjamin, S.G. "Performance of Different Soil Model Configurations in Simulating Ground Surface Temperature and Surface Fluxes", Monthly Weather Review, 125, pp 1870-1884, 1997.

17. Smirnova, T.G., Brown, J.M., Benjamin, S.G., Kim, D. "Parameterization of Cold Season Processes in the MAPS Land-Surface Scheme, Journal of Geophysics Res.", 105, pp 4077-4086, 2000.

18. Trenberth, K.E., Miller, K., Mearns, L. and Rhodes, S. "Effects of Changing Climate on Weather and Human Activities Global Change Instruction Program", National Center for Atmospheric Research, Boulder, Colorado, 2000.
19. Wicker, L.J. and Wilhelmson, R.B. "Simulation and Analysis of Tornado Development and Decay within a ThreeDimensional Supercell Thunderstorm", Journal of Atmospheric Sciences., 52, pp 2675-2703, 1995.

20. Xi, X.A. "Comparison of Two Land Surface Schemes Coupled in the Weather Research and Forecast Model", 'Thermodynamics of Atmospheres and Oceans' Fall Term Paper of School of Earth and Atmospheric Sciences, Georgia Institute of Technology, Atlanta, GA, USA, 2007. 